\title{
Restoration of thalamocortical connectivity after recovery from persistent vegetative state
}

\author{
S Laureys, M E Faymonville, A Luxen, M Lamy, G Franck, P Maquet \\ Cyclotron Research Centre, University of Liege, Belgium (S Laureys MD, A Luxen PhD, G Franck MD, P \\ Maquet MD); Department of Neurology (S Laureys, G Franck, P Maquet); and Anaesthesiology and Intensive \\ Care Medicine, Centre Hospitaller Universitaire Sart Tilman Liège, Belgium (M E Faymonville MD, M Lamy \\ $M D)$
}

\begin{abstract}
By use of $\mathrm{H}_{2}{ }^{15} \mathrm{O}$ positron emission tomography we have shown that functional connectivity between intralaminar thalamic nuclei and prefrontal and anterior cingulate cortices was altered during vegetative state but not after recovery of consciousness.
\end{abstract}

We have shown with positron emission tomography that patients in a vegetative state have an altered connectivity between frontal and parietal associative cortices. ${ }^{1}$ On the basis of the putative role of high frequency oscillatory thalamocortical circuitry underlying human consciousness, ${ }^{2}$ we assessed the integrity of thalamocortical connectivity during vegetative state and after recovery of consciousness.

A 28-year-old man was resuscitated after a cardiorespiratory arrest secondary to heroin and methadone intake. He fell into a vegetative state characterised by spontaneous eye opening without evidence of awareness; no evidence of reproducible voluntary behavioural responses to any stimuli; no evidence of language comprehension or expression; preserved sleep-wake cycles; normal cardiorespiratory function and blood pressure control; and preserved pupillary, oculocephalic, corneal, and vestibulo-ocular reflexes. Magnetic resonance imaging showed hyperintensity in bilateral internal capsules and basal ganglia on T2-weighted images. Electroencephalograms showed a diffuse non-reactive delta activity. The first cortical component of the somatosensory evoked responses was preserved and the brainstem auditory evoked potentials were normal. He remained in a vegetative state for 2 months and then recovered consciousness and partial autonomy. Functional imaging was done 2 weeks after onset of vegetative state and 4 months after recovery.

By use of the $\mathrm{H}_{2}{ }^{15} \mathrm{O}$ infusion technique, regional cerebral blood flow was measured at rest and during (left then right) auditory (95 dB clicks), and somatosensory (electrical stimulation of the median nerve at the wrist) stimulation (three scans for each of these five conditions). A psychophysiological interaction analysis ${ }^{3}$ was undertaken with statistical parametric mapping (SPM96). Compared with 18 healthy controls, there was a significant difference in modulation between both thalami and the right prefrontal (Brodmann's area 10,9, and 8) and anterior cingulate (area 24/32) cortices when the patient was in a vegetative state. After recovery, the thalamocortical modulation was no longer different from controls (table and figure). The stereotactic coordinates for the intralaminar thalamic nuclei were taken from an independent study $[x= \pm 8 ; y=-20 ; z=6]{ }^{4}$

Restoration of consciousness seems to be paralleled by the resumption of the functional relation between thalami and associative cortices. This observation supports the role of intralaminar thalamic nuclei and of the thalamocortical connections in the maintenance of consciousness in human beings.

\begin{tabular}{|c|c|c|c|c|c|}
\hline \multirow[t]{2}{*}{ Brain area (Brodmann's area) } & \multicolumn{2}{|c|}{ Stereotactic co } & \multirow{2}{*}{$\begin{array}{l}\text {-ordinates } \\
\mathrm{z}\end{array}$} & \multirow[t]{2}{*}{$Z$ score } & \multirow{2}{*}{$\begin{array}{l}\mathbf{P} \\
\text { (corrected) }\end{array}$} \\
\hline & $\mathrm{x}$ & $\mathrm{y}$ & & & \\
\hline \multicolumn{6}{|l|}{ Right hemisphere } \\
\hline Superior frontal gyrus (10) & 26 & 50 & 2 & $5 \cdot 35$ & $0-001$ \\
\hline Middle frontal gyrus (8) & 40 & 16 & 44 & $4 \cdot 87$ & $0-011$ \\
\hline Medial frontal gyrus (9) & 16 & 42 & 22 & $5 \cdot 41$ & $0-001$ \\
\hline \multicolumn{6}{|l|}{ Left hemisphere } \\
\hline Anterior cingulate gyrus $(24 / 32)$ & -12 & 32 & 18 & $4 \cdot 56$ & $0-040$ \\
\hline
\end{tabular}

Voxel corrected $(\mathrm{p}<0 \cdot 05)$. 


\section{Localisation of the peak voxels of the connectivity assessment}
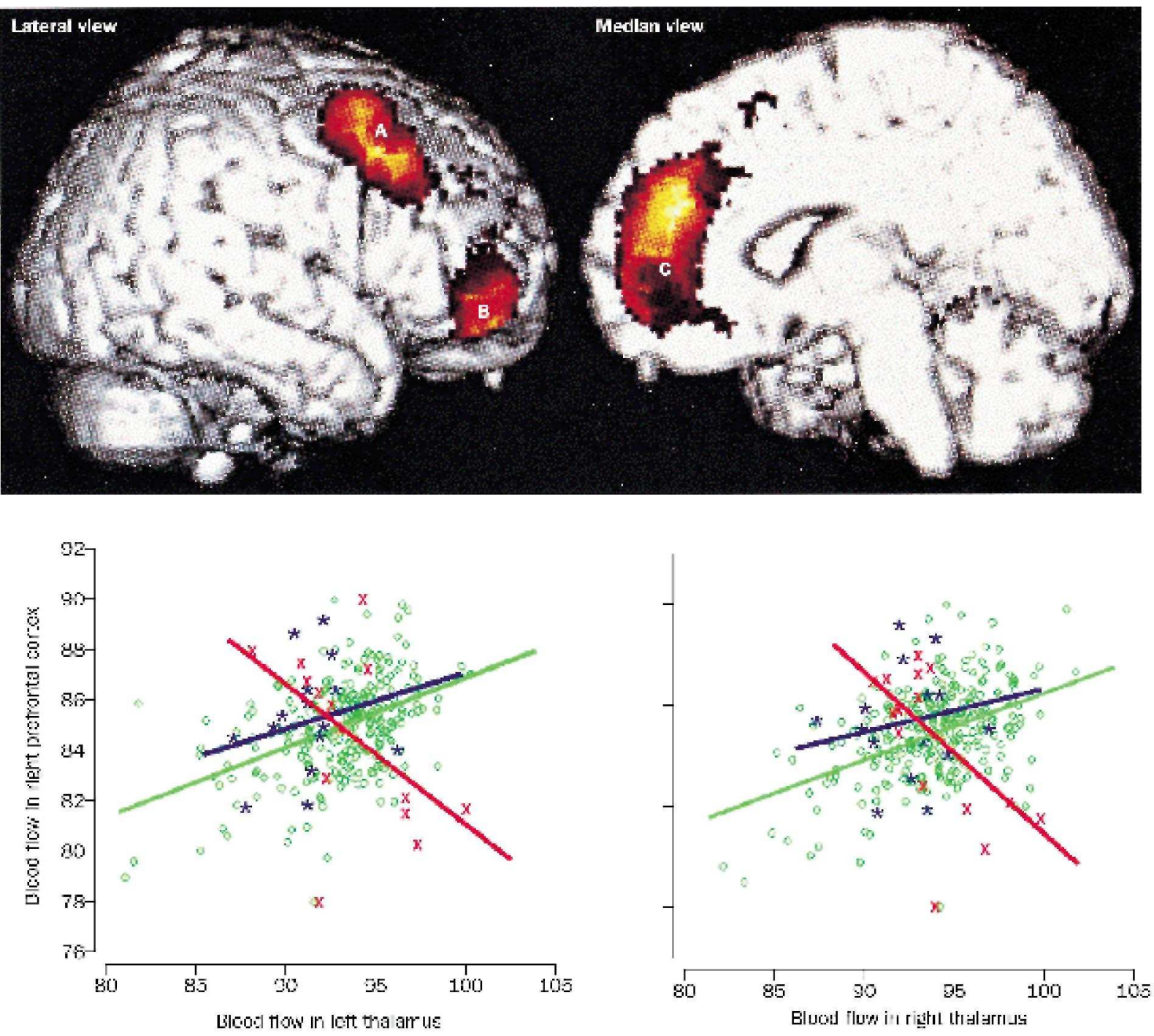

Thalamocortical disconnections in brain of a patient in vegetative state

Top: A, area 8; B, area 10; C, area 9 and 24/32. Areas in which functional connectivity with the intralaminar nuclei of both thalami was different from controls when the patient was in a vegetative state; these differences were not apparent when he recovered consciousness; shown on a surface rendered normalised manetic-resonance image (display thresholded at $\mathrm{p}<0.001$ uncorrected). Bottom: regression between activity in both thalami and right prefrontal cortex (area 10) in controls (green open circles), compared with patient in vegetative state (red crosses) and after recovery (blue asterisks). Modulation between thalami and frontal cortex is impaired during vegetative state and is not substantially different from controls after recovery.

\section{References}

1 Laureys S, Goldman S, Phillips C, et al. Impaired effective cortical connectivity in vegetative state: preliminary investigation using PET. Neuroimage 1999; 9: 377-82.

2 Llinas R, Ribary U, Contreras D, Pedroarena C. The neuronal basis for consciousness. Philos Trans R Soc Lond B Biol Sci 1998; 353: 1841-49.

3 Friston KJ, Buechel C, Fink GR Morris J, Rolls E, Dolan RJ. Psychophysiological and modulatory interactions in neuroimaging. Neuroimage 1997; 6: 218-29.

4 Kinomura S, Larsson J, Gulyas B, Roland PE. Activation by attention of the human reticular formation and thalamic intralaminar nuclei. Science 1996; 271: 512-15. 